\title{
Erratum: Insulin, C-peptide and proinsulin for the biochemical diagnosis of hypoglycaemia related to endogenous hyperinsulinism
}

D Vezzosi, A Bennet, J Fauvel ${ }^{1}$ and P Caron

Department of Endocrinology, Centre Hospitalier Universitaire Rangueil, 1 avenue Jean Poulhès, TSA 50032, 31059 Toulouse Cedex 9, France and

${ }^{1}$ Department of Biochemistry, Centre Hospitalier Universitaire Purpan, 1 place du Docteur Baylac, 31059 Toulouse Cedex 9, France

(Correspondence should be addressed to P Caron; Email: caron.p@chu-toulouse.fr)

The authors and the journal apologise for an error in the above paper which appeared in 157 (1) 75-83. In this paper, on page 77, under section entitled 'Blood glucose levels during the fast test', the second sentence should read as follows:

'At the end of the fast test, blood glucose levels were $2.0 \pm 0.3 \mathrm{mmol} / \mathrm{l}(1.2-2.4 \mathrm{mmol} / \mathrm{l})$ in patients, whereas they were $3.3 \pm 0.66 \mathbf{~ m m o l} / \mathbf{l}(2.31-5.39 \mathbf{~ m m o l} / \mathbf{l})$ in controls $(P<0.0001)$.' and not as published.

European Journal of Endocrinology 157693 